Article

\title{
Project Portfolio Selection Considering Total Cost of Ownership in the Automobile Industry
}

\author{
Seunghoon Lee * ${ }^{-}$, Young Hoon Lee and Yongho Choi \\ Department of Industrial Engineering, Yonsei University, 50 Yonsei-ro, Seodaemun-gu, Seoul 03722, Korea \\ * Correspondence: shbrandonlee@yonsei.ac.kr; Tel.: +82-2-2123-4813
}

Received: 25 June 2019; Accepted: 17 August 2019; Published: 23 August 2019

check for updates

\begin{abstract}
Project portfolio selection for developing a new product is critical to a company because the attributes of the project reflect on the price, quality, and functionality of the developed product. The market evaluates the developed product and the assessment of the product value determines its sale on the market. The project portfolio selection and sales are interconnected from a corporate perspective. The automobile industry is an industry which responds to the issue of business sustainability sensitively because their business directly relates to the environment. In this study, business sustainability was approached through the perspective of total cost of ownership (TCO) embedded into the project selection model after the attributes of the project, investment and efficiency, and the TCO of the product were combined to generate a sales function. The sales and revenue models were proposed, and the validity of the models was confirmed using a case from the automobile industry. As a result of the experiments, the sales model tended to show that the market share increased by selecting the proper number of projects to maximize sales. In contrast, the revenue model showed a tendency to select projects more than the sales model in order to maximize the profits of the company. By suggesting project selection models in a new perspective different from the ones in existing studies, this study is valuable with regard to the fact that the suggested models preserve project interrelationships, TCO, and product sales in a practical manner to enhance business sustainability.
\end{abstract}

Keywords: project management; project portfolio selection; total cost of ownership; automobile

\section{Introduction}

Business sustainability creates value for the profit of a company by taking in opportunities and handling risks derived from economic, environmental, and social development. Sustainable companies are maximizing their profit in the market for short- to long-term perspectives in consideration of economic, environmental, and social issues [1]. The automobile industry is an industry which responds to the issue of business sustainability sensitively because their business directly relates to the environment. Recently, stricter European emission standards, EURO 6, have been implemented to reduce the problem of pollution from vehicles, corresponding to sustainable conditions in the environment [2]. Such regulation can affect automobile companies in that an increase in the purchase cost of products is inevitable because the cost of new technologies dealing with more stern regulation is added to the purchase cost when developing products. Products on the market priced higher than competitors can easily be excluded as candidates by customers, thereby working as a risk factor for companies. Therefore, while developing a product following new regulations where the purchase cost of the developed product increases, an increase in the price needs to be considered in the decision-making process for project selection by companies.

Project portfolio selection is a critical decision for a company, because the selection affects the company's profit, as well as the position of the company in the market. Owing to insufficiency of 
resources, a company is generally not able to begin all projects at the same time and, thus, the decision to select one or more projects from a large number of projects is key. The portfolio selection problem has been studied in a variety of perspectives such as strategy, quality, market, and technology. As the problem is one of combinatorial optimization, many researchers have proposed methodologies for effectively selecting a project portfolio.

The portfolio selection problem was first introduced by Markowitz [3], and the notion of this problem has been addressed by several researchers. They used a fuzzy analytic network process (ANP) and an analytic hierarchy process (AHP) for evaluating a project, to solve the project portfolio selection problem. Meade and Presley [4] dealt with a research and development (R\&D) project selection problem by utilizing an ANP that did not require a hierarchical frame, while considering the interactions among decision levels more than in an AHP. Amiri [5] used two methods together to solve the project portfolio selection problem: the AHP and a fuzzy technique for order of preference by similarity to ideal solution (TOPSIS). The AHP analyzed the projects and the fuzzy TOPSIS calculated the final ranking. Mohanty et al. [6] employed fuzzy methods using the ANP to deal with a fuzzy cost analysis and Carlsson et al. [7] proposed a fuzzy mixed-integer programming model for an R\&D project selection problem. Pérez et al. [8] considered the uncertainty designed by fuzzy techniques to assist decision-makers with selection project portfolio selection and scheduling. Mohagheghi et al. [9] applied interval type-2 fuzzy sets to deal with uncertainty. They proposed the model of an R\&D project evaluation first and extended it for the project portfolio selection with the uncertainty.

Dinesh et al. [10] utilized data envelopment analysis (DEA) to select a six-sigma project. The DEA identified the projects resulting in a maximum benefit, which generated the efficiency of the six-sigma projects by providing a Pareto optimal solution. Eilat et al. [11] adopted not only DEA but a balanced scorecard (BSC) also. After embedding a BSC into the DEA, the model was tested by an industrial research laboratory to select $R \& D$ projects.

Liesiö et al. [12] solved the project selection problem by suggesting a robust portfolio modeling approach that broadens an existing preference programming method to render robustness as decision guidance. Fliedner and Liesiö [13] controlled the level of conservatism used in deciding dominance relations among project portfolios in robust project portfolio selection. Lee et al. [14] introduced an integrated approach that consists of a Delphi analytic network process concept and 0-1 goal programming to select projects. Badri et al. [15] discussed a mixed 0-1 goal programming model with a ranking method that resolves the infeasibility in project portfolio selection.

Meta-heuristic methodologies have been applied to multi-objective portfolio selection. Pareto ant colony optimization was introduced and extended by adding an integer linear programming (ILP) preprocessing procedure [16,17]. Dewi and Sawaluddin [18] addressed a multi-period project portfolio selection using an enhanced genetic algorithm (GA). With the improved GA, the result was more accurate and robust, and required less computation time than other algorithms. Panadero et al. [19] solved the stochastic project portfolio selection problem with a variable neighborhood search simhueristic.

Despite project selection being relevant to developing a product and a company's interest, studies integrating a project, product, and sales have not yet been addressed. The existing studies are mostly related to the project selection itself or approached by introducing new methodologies to select the projects, not considering market-related factors. Lee et al. [20] addressed R\&D project selection with customer-perceived value and technological potential. However, the study was not extended to consider market-related factors such as sales. Therefore, practical approaches to address the project selection problem are needed which consider a market-based perspective because project selection is related to a company's profit, either directly or indirectly.

In this study, to manage and cope with the aforementioned situations, the concept of total cost of ownership (TCO) was adopted and embedded into the project selection process to consider business sustainability and the risks in the market. 
The TCO, meaning the total cost from purchase to resell, has arisen as the main issue among customers in the automobile industry, and automobile manufacturers try to decrease the TCO in order to attract customers when developing products. Chiefly, customers who drive commercial vehicles are interested in the TCO more than others because they earn revenue from these vehicles by transporting cargo. Moreover, most of these consumers prudently choose one vehicle among several candidates by assessing the TCOs among candidate vehicles, as the purchase cost (PC) of the vehicle is costlier than a passenger car and the maintenance cost (MC) directly relates to their profit. Defining that the investment in projects is added into the PC and the efficiency of projects reduces the MC, the attributes of the project and the TCO are combined. The meaning of a reduction in the MC is that the lifecycles of items consisting of the MC are longer and there is an improvement in the product's performance. In addition, a sales function is generated by the relationship between an increase in the PC and a decrease in the MC because of selected projects. With the sales function, two project selection models, sales and revenue models, are proposed which regard the representative strategies of companies. The purpose of the sales model is to maximize the sales of the product, thereby taking the high market share in the highest range possible. The revenue model, unlike the sales model, considers the profit of the company by maximizing the revenue. In the case of the automobile industry, it is used for validating the project selection models. These models contribute to managing project selection for companies in order to handle the issues deriving from environmental regulations of the market.

The composition of this paper is as follows. First, Section 2 introduces the general TCO model and project attributes to define the correlation between the TCO and project. Section 3 outlines the project selection models along with their sales assessments, based on the TCO. In Section 4, the models based on the TCO are described, and the results of the cases are explained. Section 5 presents the conclusion of this study.

\section{Background}

\subsection{Total Cost of Ownership}

The concept of the TCO has been investigated in diverse fields, such as vendor and supplier selection, purchasing, and automobiles. Outsourcing and purchasing decisions have been studied based on analysis of the TCO [21,22]. Degraeve et al. [23] exploited the TCO concept for evaluating existing vendor selection models. A real dataset was used to compare the vendor selection models, and the mathematical programming models were found to outperform the rating and multiple item models from the TCO standpoint. Wouters et al. [24] approached enhancing sourcing decisions by applying TCO. From the perspective of a structural equations analysis, the model consisted of eight constructs hypothesized to elaborate the TCO: competitive pressure in customer markets, strategic purchasing orientation, top management support, functional management commitment, value analysis experience, adequacy of the TCO information, success of the TCO initiatives, and the use of the TCO-based review and reward systems. The data gained from the purchasing managers were used for model testing and the relationships of the constructs were found to be largely unaffected from the perspectives of the plant maintenance manager and purchasing manager. Faria et al. [25] compared electronic vehicles (EVs) and internal combustion engine vehicles (ICEVs). The EVs and ICEVs were particularly compared from an economic viewpoint employing the TCO. Al-Alawi and Bradley [26] defined the parameters of a TCO model of plug-in hybrid electric vehicles (PHEVs) and used a model to calculate the TCO of PHEVs as opposed to that of a conventional vehicle (CV). In addition to the TCO model, payback periods of the CV and PHEVs were compared to evaluate the value of purchasing PHEVs. Lastly, a preference survey in the market was conducted to quantify the expenses and advantages of having PHEVs to customers. Dumortier et al. [27] examined the preferences of customers for purchasing CVs and EVs and the preferences were calculated on the basis of their fuel costs for five years and the TCO. As the operating cost is the primary issue in the automobile industry, researchers have studied the 
TCO to compare the cost of EVs to a CV [28,29]. Wu et al. [30] proposed a probabilistic simulation model to evaluate the present and future TCO of vehicles.

Referring to Reference [26], the generalized TCO model of a product is composed of the following. The TCO consists of the PC, MC, and salvage value (SV) or resale value. As mentioned above, the PC is literally the purchase cost of the product. The MC is the total cost for maintenance of the performance of the product. In that regard, let $j$ be an item of the product that needs to be replaced regularly while owning the product. Thus, the sum of the costs of item $j$ of the product is equal to $\sum_{j} M C_{j}$. Lastly, the $\mathrm{SV}$ indicates the value of the product when reselling it. During an ownership period $N$, the value drops, following the depreciation rate of the product. Assuming that the product depreciates as a function for the ownership planning period, the SV can be expressed as $1-f(N) \cdot P C$. Therefore, the equation below shows the general model of the TCO.

$$
T C O=P C+\sum_{j} M C_{j}-S V=P C \cdot(1-f(N))+\sum_{j} M C_{j}
$$

\subsection{Project Attributes}

Project management can be described as the planning and monitoring of a project for the timely achievement of the project objectives and considers the cost, quality, and performance of projects [31]. Um and Kim [32] utilized structural equation modeling to prove a new product development project uncertainty that influences on the project performance. Tran and Long [33] considered the time, the cost, and the risk of projects for the project scheduling solved by the presented effective algorithm. Tofighian et al. [34] solved the multi-period project portfolio selection problem, which, in each time period, deals with risks, stochastic incomes, and investing extra money. Also, the synergies among projects are regarded as the attribute, where interdependency exists among them. Litvinchev et al. [35] proposed a multi-objective mixed-integer linear programming model for an R\&D projects with the synergies and funds. Li et al. [36] considered project interdependency and divisibility, the latter of which can be defined as interruptions due to the presence of unexpected circumstances in project portfolio selection. Schaeffer and Cruz-Reyes [37] presented a MILP model for project portfolio selection to deal with dependencies and their effects throughout synergies.

There exist many project attributes that can be considered in the project selection problem, as described above. In this study, investment and efficiency of the project were selected because those factors obviously have an impact on the TCO of the product. Next, how the selected attributes of the project affect the components of the TCO is shown. First, as aforementioned, each project, $k$, has two attributes, investment and efficiency: let $F_{k}$ denote the investment of the project $k, e_{k j}$ denotes the efficiency factor (\%) which reduces the item $j$ 's MC for a product by the project $k$ investment. So, $\sum_{k} F_{k} x_{k}$ is the total investment of the company and $\sum_{k} e_{k j} x_{k}$ is the total efficiency of the selected projects for item $j$ of the MC, where $x_{k}$ denotes the decision variable for project $k$ selection. The total efficiency is assumed to follow a certain function $\mathrm{g}(x)$, which is denoted by $\mathrm{g}\left(\sum_{k} e_{k j} x_{k}\right)(\%)$, and thereby $\sum_{j} M C_{j}\left(1-\mathrm{g}\left(\sum_{k} e_{k j} x_{k}\right)\right)$ is equal to a new MC $\left(\mathrm{MC}^{\prime}\right)$ of developing a product, meaning the cost was reduced from the sum of item $j$ 's MC as much as the total efficiency percentage, followed by a certain function. Another assumption of the project is provided as below.

- All projects are commenced simultaneously;

- The interdependency of projects is not considered;

- Projects are not divided into a set of actives.

Project portfolio management is a commonly employed technique to align a project portfolio with strategic goals [38]. In the next section, two project selection models, sales and revenue, are described for the goal of maximizing the market share and profit to enhance business sustainability in the market as the representative strategies of companies after elaborating how the sales function of a product is built on the basis of the TCO and the attributes of the project. 


\section{Models}

This section presents a detailed explanation of the sales function of the product and the project selection models, which has two parts. First, the TCO and the attributes of the project are combined to generate the new TCO $\left(\mathrm{TCO}^{\prime}\right)$ and then the sales function is formulated based on the TCO'. Second, with the sales function, the sales and the revenue models are proposed to select a set of projects for maximizing the market share and profit, respectively. The goal of the company's project is assumed for developing a new version of an existing product.

When a company develops a new product or a new version of an existing product, the investment and efficiency of the project affect its TCO components. For example, the investment of the company is included in the PC of the product to recover it, and the efficiency results in the function or performance of the product being improved. With this perspective, as the company's total investment is $\sum_{k} F_{k} x_{k}$, as discussed in the previous section, it reflects on the PC of the new product in such a way as to be distributed to the PC of each product. During the upgrade of a product, the PC increase is added to the original PC. If the investment in the project is added for the product PC, then the purchasing cost will increase by $\triangle P C=\alpha \cdot \frac{\sum_{k} F_{k} x_{k}}{n \cdot y}$, where $\alpha$ is the PC increase factor owing to the unit investment for the product; $n$ is the sales period plan in consideration; and $y$ is the sales volume of the product. Hence, the new PC of the product, $\mathrm{PC}^{\prime}$, is as shown below.

$$
P C^{\prime}=P C+\alpha \frac{\sum_{k} F_{k} x_{k}}{n \cdot y}
$$

With $M C^{\prime}=\sum_{j} M C_{j}\left(1-\mathrm{g}\left(\sum_{k} e_{k j} x_{k}\right)\right)$, the TCO of the new product is formulated as below.

$$
T C O^{\prime}=\left(P C+\alpha \frac{\sum_{k} F_{k} x_{k}}{n \cdot y}\right) \cdot(1-f(N))+\sum_{j} M C_{j}\left(1-\mathrm{g}\left(\sum_{k} e_{k j} x_{k}\right)\right)
$$

Next, establishing the sales volume of the product $y$ is explained in detail. If the performance upgrading of the project progresses, the new product shows favorable sales, and the sales can be altered depending on the TCO change. Letting $y_{0}$ be the baseline sales expectation of product $s$ without any investment, the new sales can be predicted as $y=y_{0}\left[\beta_{1} \cdot \frac{\Delta M C}{\sum_{j} M C_{j}}-\beta_{2} \cdot \frac{\Delta P C}{P C}\right]$, as the MC decrease is advantageous to the sales increase with a rate of $\beta_{1}\left(\beta_{1} \geq 0\right)$, and the PC increase is disadvantageous to the sales increase, with a rate of $\beta_{2}\left(\beta_{2} \geq 0\right)$. Hence, Equation (4) shows the sales function established by applying the TCO.

$$
\begin{gathered}
y=y_{0}\left[\beta_{1} \cdot \frac{\sum_{j} M C_{j} \cdot g\left(\sum_{k} e_{k j} x_{k}\right)}{\sum_{j} M C_{j}}-\beta_{2} \cdot \frac{\alpha \cdot \sum_{k} F_{k} x_{k} /(n \cdot y)}{P C}\right] \\
y^{2}-\frac{y_{0} \cdot \beta_{1} \cdot\left(\sum_{j} M C_{j} \cdot g\left(\sum_{k} e_{k j} x_{k}\right)\right)}{\sum_{j} M C_{j}} \cdot y+\frac{\alpha \cdot \beta_{2} \cdot y_{0}\left(\sum_{k} F_{k} x_{k} / n\right)}{P C}=0 \\
n \cdot \sum_{j} M C_{j} \cdot P C \cdot y^{2}-n \cdot y_{0} \cdot \beta_{1}\left(\sum_{j} M C_{j} \cdot g\left(\sum_{k} e_{k j} x_{k}\right)\right) \cdot P C \cdot y+\alpha \cdot \beta_{2} \cdot y_{0}\left(\sum_{k} F_{k} x_{k}\right) \cdot \sum_{j} M C_{j}=0
\end{gathered}
$$


By rearranging the sales function, the quadratic sales function is derived. As the role of the MC reduction is to increase sales and that of the PC is to decrease sales, the condition for the lower bound of the sales, Equation (5), can be written as follows:

$$
\begin{gathered}
\Delta M C>\Delta P C \\
\sum_{j} M C_{j} \cdot g\left(\sum_{k} e_{k j} x_{k}\right)>\frac{\alpha \cdot \sum_{k} F_{k} x_{k}}{n \cdot y} \\
y \geq \frac{\alpha \cdot \sum_{k} F_{k} x_{k}}{n \cdot \sum_{j} M C_{j} \cdot g\left(\sum_{k} e_{k j} x_{k}\right)}
\end{gathered}
$$

Using the sales function and the condition, two mathematical models are proposed in the following section.

\subsection{Sales Model}

In this section, the mathematical project selection model in terms of sales is explained. The goal of the sales model is to maximize the sales volume to increase market share. The sales model is presented below.

$$
\begin{gathered}
\text { Max Sales }=y \\
\text { subject to } \\
n \cdot \sum_{j} M C_{j} \cdot P C \cdot y^{2}-n \cdot y_{0} \cdot \beta_{1}\left(\sum_{j} M C_{j} \cdot g\left(\sum_{k} e_{k j} x_{k}\right)\right) \cdot P C \cdot y+\alpha \cdot \beta_{2} \cdot y_{0}\left(\sum_{k} F_{k} x_{k}\right) \cdot \sum_{j} M C_{j}=0 \\
y \geq \frac{\alpha \cdot \sum_{k} F_{k} x_{k}}{n \cdot \sum_{j} M C_{j} \cdot g\left(\sum_{k} e_{k j} x_{k}\right)} \\
x_{k}=\left\{\begin{array}{c}
1, \quad \begin{array}{c}
\text { if project } k \text { is selected } \\
0, \text { otherwise }
\end{array}, \quad \forall k
\end{array}\right.
\end{gathered}
$$

Equation (6) is the objective function of the model to maximize sales. Equation (7) is the quadratic function to calculate the sales discussed above. Equation (8) means the minimum sales occurred by the project selection and Equation (9) is the constraint that the sales are greater than the baseline sales. Lastly, Equation (10) is a decision variable for project $k$.

\subsection{Revenue Model}

The revenue model is based on the concept that maximizes the company's profit in the market. The revenue is assumed to be calculated using the sales multiplied by the PC and, subsequently, the revenue model is proposed in the following manner.

$$
\begin{gathered}
\text { Max Revenue }=y \cdot P C^{\prime} \\
\text { subject to } \\
n \cdot \sum_{j} M C_{j} \cdot P C \cdot y^{2}-n \cdot y_{0} \cdot \beta_{1}\left(\sum_{j} M C_{j} \cdot g\left(\sum_{k} e_{k j} x_{k}\right)\right) \cdot P C \cdot y+\alpha \cdot \beta_{2} \cdot y_{0}\left(\sum_{k} F_{k} x_{k}\right) \cdot \sum_{j} M C_{j}=0 \\
y \geq \frac{\alpha \cdot \sum_{k} F_{k} x_{k}}{n \cdot \sum_{j} M C_{j} \cdot g\left(\sum_{k} e_{k j} x_{k}\right)}
\end{gathered}
$$




$$
x_{k}=\left\{\begin{array}{c}
1, \text { if project } k \text { is selected } \\
0, \text { otherwise }
\end{array}, \quad \forall k\right.
$$

From Equations (12)-(14), they are the same as Equations (7), (8), and (10).

\section{Empirical Experiment}

This section elaborates on the methods for the TCO and the project selection models. First, a commercial vehicle was selected as a product for the TCO, because customers consider the TCO as a top priority when buying one. The purpose of the vehicles was to transport cargoes. Therefore, the MC was a critical factor, as it directly related to a customer's profit. In this study, an Xcient (540 ps, automatic transmission, Euro6, 2015) was chosen as the product for the TCO.

Xcient is a type of commercial vehicle and which has been outselling other types for transporting cargo. In addition, this vehicle has the most shared components with similar types of vehicles released by other automobile manufacturers. Second, the proposed models exhibit non-linearity and deal with a combinatorial optimization problem. Enumeration is employed to solve the problem. The advantage of enumeration is its ability to find an optimal solution although the problem is non-linear. However, the computational time exponentially increases when the size of the problem is larger. All information was collected from the Korean market so that the cost was based on the Korean currency (W) in terms of the cost of the TCO and in the results. The value of 1000 is tantamount to one US dollar on average.

\subsection{Data Collection}

\subsubsection{Salvage Value}

The salvage value (SV) of a product is decided mainly on what market the product belongs to. For example, in the automobile market, diverse factors such as the color, options, and vehicle brand influence the SV of a vehicle.

In this study, the correlation between these factors and the SV was analyzed. However, there was an insufficiency in data for the appointed vehicle in the used car market, because it was only released three years ago. Hence, this study referred to data in a report issued by the Korean Ministry of the Interior and Safety in 2018. The SV of the truck concerning a business purpose is listed in Table 1, as most commercial vehicles are used for businesses. It can be seen that the SV of the vehicle at six years remains at $10 \%$ of the PC. Based on Table 1, the depreciation rate occurring every year was calculated, assuming that the SV followed $f(N)=\alpha^{N} \cdot P C$, where the $\alpha$ value was $72 \%$.

Table 1. Statutory standard price of fair market value.

\begin{tabular}{cccccccccc}
\hline & Purpose & Durable Year & $<\mathbf{1}$ & $\mathbf{1}$ & $\mathbf{2}$ & $\mathbf{3}$ & $\mathbf{4}$ & $\mathbf{5}$ & $\mathbf{6}$ \\
\hline Truck & Business & 6 & 0.702 & 0.561 & 0.463 & 0.316 & 0.219 & 0.153 & 0.100 \\
\hline
\end{tabular}

\subsubsection{Maintenance Items}

The maintenance items and the cost of each item vary from one product to the other and from one repair shop to the other. In this study, the fuel, component, and tire costs were selected as the maintenance items, and their cost information was obtained from the automobile's website, the repair shop selected by the automobile manufacturer, news in terms of commercial vehicles, and formal and reliable websites. 


\section{Fuel Cost}

The fuel cost (FC) accounts for a substantial proportion of the MC. Fuel consumption, among other elements, is an expense incurred by drivers. The calculation of the FC for ownership planning is done in the following manner:

$$
\mathrm{FC}(W)=\mathrm{N} \cdot \frac{\text { Fuel price }(\mathrm{km} / \ell) \times \text { Distance }(\mathrm{km})}{\text { Fuel consumption }(\mathrm{km} / \ell)}
$$

$N$ is the ownership period. The fuel price was 1391 which was the average domestic normal gas price in 2018, according to data provided by the Korean National Oil Corporation [39]. The price was fixed for future fuel prices in the TCO calculation. In this regard, fuel efficiency depended on conditions and situations such as cargo, driving habits, driving experience, and the surface of roads. Thus, the fuel efficiency was obtained from the "Xcient fuel efficiency master competition" [40] in 2016. The vehicles were driven on the same route without cargo, and the average was $6.3(\mathrm{~km} / \ell)$.

\section{Component Cost}

The component cost (CC) refers to the expense of the vehicle parts that are periodically replaced. This replacement is important for performance maintenance as it is directly related to fuel consumption, which impacts drivers' profit. As the vehicle consists of 2 to 3 million parts, they are selected referring to a list of regular inspection [41], and a survey conducted in an official repair shop selected by the automobile manufacturer.

The cost of each part is the sum of the following components: cost of the part itself, labor cost, and tax. Replacement condition is assumed to be harsh as drivers are known to operate their vehicles to the maximum extent to gain more profit when delivering the cargo to earn money. To calculate the CC, we assumed $p$ to be a part, and the number of times a replacement was used was obtained by dividing the distance by the replacement cycle. The calculation of the CC for $N$ was calculated as shown below in reference to Table 2.

$$
\mathrm{CC}(\mathbb{W})=\mathrm{N} \cdot \sum_{\mathrm{p} \in \mathcal{P}} \frac{\text { Cost }_{\mathrm{p}}(W) \times \text { Distance }(\mathrm{km})}{\text { Replacement cycle }_{\mathrm{p}}(\mathrm{km})}
$$

Table 2. Various parts and their costs.

\begin{tabular}{cccc}
\hline Part & $\begin{array}{c}\text { Replacement } \\
\text { Cycle (km) }\end{array}$ & $\begin{array}{c}\text { Replacement } \\
\text { Cycle (Month) }\end{array}$ & Cost (W) \\
\hline Engine oil & 30,000 & 6 & 220,000 \\
Engine oil filter & 30,000 & 6 & 58,000 \\
Fuel filter & 40,000 & - & 46,000 \\
Air cleaner & 30,000 & 6 & 93,000 \\
Main filter & 40,000 & 8 & 57,000 \\
Closed crankcase ventilation filter & 100,000 & 12 & 50,000 \\
Transmission oil & 60,000 & 12 & 170,000 \\
Rear axle oil & 60,000 & 6 & 105,000 \\
Auxiliary power unit & 50,000 & 12 & 118,000 \\
Air condition filter & 60,000 & 12 & 31,000 \\
Air cleaner filter & 30,000 & - & 52,800 \\
Transmission filter & 24,000 & - & 109,000 \\
\hline
\end{tabular}

\section{Tire Cost}

Commercial vehicles have more wheels, unlike a passenger car. The appointed vehicle consists of three shafts and needs a total of 10 tires. The point at which tires need to be replaced is dependent on road conditions, the driver's habits, etc. Normally, tires are replaced when they are worn out according to the wear indicator on them. Table 3 refers to a report named "Research on Optimal Requirement Type for Each Group of Military Standard Commercial Truck", issued by the Korea 
Automotive Technology Institute in 2013. The wear rates are presented according to the size of the truck at certain speeds $(\mathrm{km} / \mathrm{h})$.

Table 3. Wear rates of tires according to the speed and size of the truck $(\% / 1000 \mathrm{~km})$.

\begin{tabular}{ccccccccccc}
\hline Speed $\mathbf{( k m} / \mathbf{h})$ & $\mathbf{1 0}$ & $\mathbf{2 0}$ & $\mathbf{3 0}$ & $\mathbf{4 0}$ & $\mathbf{5 0}$ & $\mathbf{6 0}$ & $\mathbf{7 0}$ & $\mathbf{8 0}$ & $\mathbf{9 0}$ & $\mathbf{1 0 0}$ \\
\hline Small size & 0.6 & 1.1 & 1.8 & 2.5 & 3.1 & 4.0 & 5.0 & 6.1 & 7.4 & 8.8 \\
Medium size & 1.9 & 1.9 & 2.7 & 3.7 & 4.9 & 6.1 & 7.4 & 9.2 & 11.0 & 13.2 \\
Large size & 1.9 & 3.3 & 5.0 & 7.1 & 9.3 & 12.3 & 15.4 & 19.6 & 24.7 & 30.3 \\
\hline
\end{tabular}

As the appointed vehicle belongs to the large size category and is capable of operating in a wide range of speeds, the average of the wear rates was used, which was $12.89(\% / 1000 \mathrm{~km})$. Therefore, the replacement cycle of all tires occurred every $7758 \mathrm{~km}$ for the TCO calculation.

$$
\mathrm{TC}(W)=\mathrm{N} \cdot 10 \cdot \frac{\operatorname{Cost}(\$) \times \text { Distance }(\mathrm{km})}{\text { Replacement cycle }(\mathrm{km})}
$$

\subsubsection{Other Factors}

This section explains why other factors such as taxes, insurances, subsidies, urea costs, and interest are excluded from the TCO calculation.

There are two types of tax: automobile tax and acquisition tax. The automobile tax varies depending on the type, purpose, and even the displacement of the vehicle. The automobile tax of the appointed vehicle is $\$ 36,000$, which is remarkably small compared to other costs. Hence, it was excluded in the TCO calculation in this study. The acquisition tax is dependent on the type and purpose of the vehicle. For business purposes, the tax is $4 \%$ of the PC, excluding a value-add tax $(10 \%)$.

Another factor is the delivery fee of the vehicle. When a driver delivers the vehicle from a delivery center to a customer, compared to a passenger car, it is more expensive, but it is still only a small proportion of the TCO; thus, it was not added to the TCO.

Next, the insurance cost is calculated by the customer's credit and type of vehicle, as well as the guaranteed items in the insurance. As the amount is unspecified and small, it was eliminated from the list for the TCO.

The use of urea has been mandatory when fueling up a commercial vehicle since 2015, owing to the EURO 6 standard regulation, as it reduces NOx. Therefore, the importance of urea is gradually becoming more remarkable. According to reports [42], an $8 \times 4$ dump truck, a similar version of the appointed vehicle, consumes $0.3 \ell$ over $153.9 \mathrm{~km}$, and the price of urea per liter is 1200 . There is no doubt that the use of urea is one of the characteristics of a commercial vehicle. However, in terms of the cost, it is still a small amount.

Lastly, most customers purchase the vehicle on installments, thus, the interest rate is also a factor to be considered when calculating the TCO. However, as the interest rate is dependent on the credit of customers and the amount of the interest is small, it was excluded from the TCO calculation in the study.

\subsubsection{TCO of the Sample Vehicle}

Table 4 shows the TCO of the vehicle based on the discussed factors and the assumptions. The currency was Korean Won. With regard to the customer's information, the ownership planning $(N)$ was 10 years and the distance per year was $250,000 \mathrm{~km}$. 
Table 4. Total cost of ownership of the vehicle.

\begin{tabular}{|c|c|c|c|c|c|c|c|}
\hline Xcient & $\begin{array}{c}\text { Purchase } \\
\text { Cost (PC) } \\
\left(\$ 10^{6}\right)\end{array}$ & $\begin{array}{c}\text { Fuel Cost } \\
\text { (FC) } \\
\left(\$ 10^{6}\right)\end{array}$ & $\begin{array}{c}\text { Component } \\
\text { Cost (CC) } \\
\left(\$ 10^{6}\right)\end{array}$ & $\begin{array}{c}\text { Tire Cost } \\
\text { (TC) } \\
\left(\$ 10^{6}\right)\end{array}$ & $\begin{array}{c}\text { Salvage } \\
\text { Value (SV) } \\
\left(\$ 10^{6}\right)\end{array}$ & $\begin{array}{c}\text { TCO } \\
\left(\$ 10^{6}\right)\end{array}$ & $\begin{array}{c}\text { TCO } \\
\text { (\$10 } / \text { Month) }\end{array}$ \\
\hline & 155.34 & 551.98 & 279.58 & 338.36 & 5.82 & 1319.44 & 10.955 \\
\hline
\end{tabular}

\subsection{Parameters}

The parameters, $n, \alpha, \beta_{1}, \beta_{2}$, and the function $\mathrm{g}(\mathrm{x})$ were set for the models as follows. The sales period plan in consideration, $n$, was categorized as short-, medium-, or long-term. Therefore, anticipating that a vehicle could be sold on the market with a different plan, the company's investing strategy would change. In this study, the short-, medium-, or long-term were assumed as 3, 5, and 10 years, respectively. $\alpha$ was the factor deciding the amount of the investment to add to the PC, and its value was set between 0 and 1 . The investment can be included in the purchase price, depending on the situation the company is dealing with. Thus, the value of $\alpha$ was regarded as $0.3,0.5,0.7$, and 1 . As $\beta_{1}$ and $\beta_{2}$ denote the degree of influence on sales in the market, they were divided into three cases, $1: 1,1: 0.5$, and 1:2, to check the market's response on the variation of the costs. In other words, $\beta_{1}$ and $\beta_{2}$ were shown as the existence of competitors in the market. For example, when $\beta_{1}$ is 0.5 , the company does not take full advantage of the reduction in the MC by the selected projects. Thus, the sales do not fully increase due to the reduction because other competitors make similar efforts. Similarly, when setting $\beta_{2}$ to 0.5 , the purchase cost of a new product is favorable in the market due to the cheaper price than other competitors.

Lastly, $\mathrm{g}(\mathrm{x})$ is a certain function that shows the degree of efficiency when the project decreases the MC. The function can exist largely in two forms: linear and non-linear. Based on the idea that there exist limitations in the improvement of a project owing to endurance, finance, and so forth, the function was assumed as a logarithmic function to apply such limitations, and its base was 1.1 as well.

\subsection{Analysis}

This section discusses how the models were tested, using the data mentioned above, and implemented, coded in the Java language on a $3.20 \mathrm{GHz}$ Intel-core i7 and with $16 \mathrm{~GB}$ memory. For 20 projects and 30 projects, the computation time averaged $1 \mathrm{~s}$ and $300 \mathrm{~s}$, respectively.

Computation could not be exercised for 40 projects in our computer environment due to the large number of combinations resulting from such a number $\left(2^{40}\right)$ in order to be selected. This study did not focus primarily on addressing the issue of the number of projects and, instead, focused on the introduction of new models, and, in this regard, 20 projects were considered for the evaluation of the models.

The elements of each project were assumed and generated by the following. Assuming the total budget of the company was $\$ 300$ billion, the investment of each project was generated between $\$ 5$ billion to $\$ 30$ billion, on the understanding that the sum of the investment of the projects could not exceed the budget. The efficiency was generated randomly, because the details of the information regarding the projects were not exposed to the public. The unit of efficiency was a percentage, which reduced the amount as much as the percentage from the original cost when the project was selected. There were three groups of projects, which were categorized by the number of items affected.

The data used for the models are listed in Table 5. It assumed that the investment amount did not follow the efficiency ratio; larger investment did not result in higher efficiency, as there exist cases for high-efficiency rates and small investments and low-efficiency rates and large investments. As assumed and mentioned, the items of the MC, $e_{k j}$ (i.e., the fuel, component, and tire items), were affected by the efficiency of the project $k$.

Several cases $\left(n, \alpha, \beta_{1}, \beta_{2}\right)$ were tested: the cases showed how the models work depending on the alteration of the parameters in Table 6 . The results of the experiments were applied for the enumeration, which found the optimal value, as the models exhibited non-linearity and dealt with a combinatorial 
optimization problem. First, when $n$ was longer, the models tended to select more projects, which spends more investment on upgrading the vehicle, as the investment can be distributed to the PC in the long term. When the market was favorable for the reduction in the MC $\left(\beta_{1}>\beta_{2}\right)$, the models increased the investment. In contrast, a new $\mathrm{PC}, \mathrm{PC}^{\prime}$, increase was expected to have a more negative impact on the market $\left(\beta_{1}<\beta_{2}\right)$, and the models were expected to decrease investment.

Table 5. Project attribute data.

\begin{tabular}{ccccc}
\hline Project $\mathbf{k}$ & $\boldsymbol{F}_{\boldsymbol{k}}\left(\mathbf{W} 10^{9}\right)$ & $\boldsymbol{e}_{\boldsymbol{k} \mathbf{1}}(\mathbf{\%})$ & $\boldsymbol{e}_{\boldsymbol{k} \mathbf{}} \mathbf{( \% )}$ & $\boldsymbol{e}_{\boldsymbol{k} 3}(\mathbf{\%})$ \\
\hline 1 & 6.5 & 20 & 10 & 5 \\
2 & 25.4 & 15 & 10 & 15 \\
3 & 17.85 & 10 & 15 & 2 \\
4 & 9.3 & 30 & 25 & 10 \\
5 & 17.05 & 10 & 25 & 15 \\
6 & 8.95 & 40 & 10 & 20 \\
7 & 22.9 & 15 & 15 & 2 \\
8 & 15.55 & 10 & 20 & 25 \\
9 & 18.9 & 5 & 20 & 25 \\
10 & 7.35 & 5 & 25 & 15 \\
11 & 10.6 & 10 & 25 & 0 \\
12 & 12.5 & 15 & 15 & 20 \\
13 & 12 & 25 & 0 & 25 \\
14 & 8.45 & 25 & 0 & 15 \\
15 & 11.35 & 0 & 15 & 0 \\
16 & 17 & 15 & 15 & 15 \\
17 & 6.25 & 20 & 25 & 0 \\
18 & 5 & 0 & 15 & 0 \\
19 & 21.15 & 25 & 20 & 25 \\
20 & 12 & 25 & 25 & 25 \\
\hline
\end{tabular}

Table 6. Case results.

\begin{tabular}{|c|c|c|c|c|c|c|}
\hline Case $\left(n, \alpha, \beta_{1}, \beta_{2}\right)$ & Model & $\begin{array}{l}\text { Sales/Year } \\
\text { (Vehicles) }\end{array}$ & $\begin{array}{l}\text { Revenue/Year } \\
(\$ 10,000)\end{array}$ & $\begin{array}{l}\sum_{k} F_{k} x_{k} \\
\left(\mathbf{W} 10^{8}\right)\end{array}$ & $\begin{array}{c}\mathrm{PC}^{\prime} \cdot(1-f(N)) \\
(\$ 10,000)\end{array}$ & $\begin{array}{c}\mathrm{MC}^{\prime} \\
(\$ 10,000)\end{array}$ \\
\hline 1 & Sales & 730 & $14,131,895$ & 833 & 18,608 & 54,361 \\
\hline$(3,0.3,1,1)$ & Revenue & 673 & $19,331,341$ & 2660.5 & 27,625 & 46,634 \\
\hline 2 & Sales & 710 & $12,993,153$ & 588 & 17,608 & 57,403 \\
\hline$(3,0.5,1,1)$ & Revenue & 532 & $17,145,387$ & 2660.5 & 30,972 & 46,634 \\
\hline 3 & Sales & 694 & $12,004,496$ & 365 & 16,638 & 62,253 \\
\hline$(3,0.7,1,1)$ & Revenue & 536 & $14,424,130$ & 1825 & 25,857 & 48,619 \\
\hline 4 & Sales & 676 & $11,523,233$ & 302.5 & 16,386 & 64,382 \\
\hline$(3,1,1,1)$ & Revenue & 594 & $12,535,765$ & 988.5 & 20,283 & 53,077 \\
\hline 5 & Sales & 701 & $11,776,470$ & 438.5 & 16,155 & 60,395 \\
\hline$(5,1,1,1)$ & Revenue & 611 & $12,889,383$ & 1696.5 & 20,295 & 49,142 \\
\hline 6 & Sales & 730 & $12,188,228$ & 833 & 16,049 & 54,361 \\
\hline$(10,1,1,1)$ & Revenue & 673 & $13,123,507$ & 2660.5 & 18,754 & 46,634 \\
\hline 7 & Sales & 710 & $12,993,153$ & 588 & 17,608 & 57,403 \\
\hline$(3,1,1,0.5)$ & Revenue & 532 & $17,145,387$ & 2660.5 & 30,972 & 46,634 \\
\hline 8 & Sales & 730 & $13,021,228$ & 833 & 17,146 & 54,361 \\
\hline$(5,1,1,0.5)$ & Revenue & 673 & $15,784,007$ & 2660.5 & 22,556 & 46,634 \\
\hline 9 & Sales & 754 & $13,025,331$ & 1306 & 16,619 & 50,940 \\
\hline$(10,1,1,0.5)$ & Revenue & 743 & $14,203,373$ & 2660.5 & 18,398 & 46,634 \\
\hline 10 & Sales & 640 & $10,455,186$ & 152 & 15,714 & 72,215 \\
\hline$(3,1,1,2)$ & Revenue & 620 & $10,642,177$ & 302.5 & 16,517 & 64,382 \\
\hline 11 & Sales & 667 & $10,851,462$ & 245 & 15,659 & 66,847 \\
\hline$(5,1,1,2)$ & Revenue & 647 & $11,069,312$ & 503.5 & 16,448 & 59,002 \\
\hline 12 & Sales & 701 & $11,337,970$ & 438.5 & 15,553 & 60,395 \\
\hline$(10,1,1,2)$ & Revenue & 689 & $11,550,666$ & 833 & 16,114 & 54,361 \\
\hline
\end{tabular}

In the case of the sales model, when the total investment added to the PC was less, the model invested more money to maximize the sales, as the sales model is sensitive to changes in the investment. 
In contrast, the revenue model selected all projects in the cases where $\alpha$ was 0.3 and 0.5 . Over $70 \%$ of the total investment added to the PC caused the model to change the selection of the projects.

The base of the logarithmic function played a role in how the total sum of the selected efficiency affected the reduction in the MC. Therefore, according to the change in the base in Figure 1, the MC was largely altered, which resulted in different objective values. When the base increased, the sales in the sales model and the revenue model decreased, but the sales in the revenue model rose by between 1.7 and 1.8. While the amount of the reduction in the MC decreased due to the base increase; by and large, the models decreased the total investment and thereby the $\mathrm{PC}^{\prime}$ decreased.
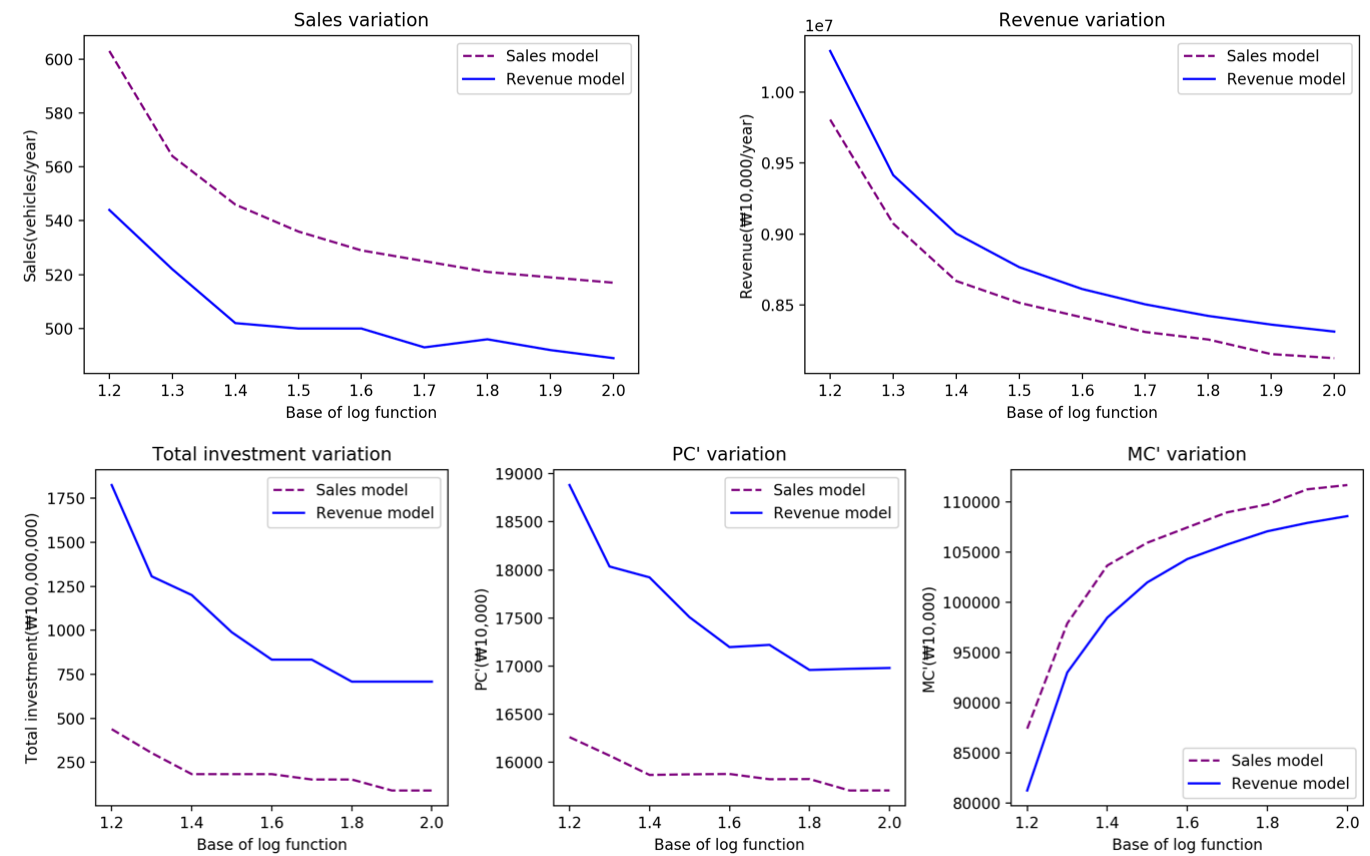

Figure 1. Variation of sales, revenue, total investment, new purchase cost, and new maintenance cost.

To evaluate the results of the cases which are shown in Table 6, four performance indices were applied; the variation of the sales (SI, $\left.\frac{\Delta \text { Sales }=y-y_{0}}{\sum_{k} F_{k} x_{k}}\right)$, revenue (RI, $\left.\frac{\Delta \text { Revenue }=y \cdot P C^{\prime}-y_{0} \cdot P C}{\sum_{k} F_{k} x_{k}}\right)$, and TCO (TI, $\frac{\Delta \mathrm{TCO}=\mathrm{TCO}-\mathrm{TCO}^{\prime}}{\sum_{\mathrm{k}} \mathrm{F}_{\mathrm{k}} \mathrm{x}_{\mathrm{k}}}$ ) against the total investment and the payback period (PP,

$\sum_{k} F_{k} x_{k}$ ) was calculated on a basis of the investment against $15 \%$ of the operating profit of Revenue $\times$
the revenue.

As listed in Table 7 , when $\beta_{1}$ was less than $\beta_{2}$, all indices were greater in the sales and revenue models. As investment decreased, the value of the indices was higher. For the same reason, and comparing Cases 4, 5, and 6, the value of the indices was found to be lower while $n$ was longer. Interestingly, when the market was favorable for the reduction of the MC, the TI value increased when $n$ was longer in the revenue model, unlike other cases. As the revenue model selected all projects, the TCO decreased owing to the decrease in the purchasing cost by increasing the sales.

To observe the trend of the values of the sales and revenue models with market change, Case 10 $\left(1,1, \beta_{2}\right)$ was tested. In Figure 2, when $\beta_{2}$ increased gradually, the sales model decreased the total investment. By doing so, the sales and revenue both saw a declining trend. However, the revenue model, unlike the sales model, increased sales, when the total investment dropped. Additionally, it was noted that SI, RI, and TI all showed an increase owing to the reduction in the total investment. For example, when $\beta_{2}$ was 0.5 and 1.0, despite the sales being higher at 0.5 , the SI was less than 1.0, owing to the reduction in the total investment, and the TI and RI were shown to have similar aspects to the SI. Figure 3 shows the trends according to the ratio of the total investment added to the PC in Case $3(\alpha, 1$, 
1). The sales model showed similar aspects to the market change. However, the revenue model had different aspects. For example, the sales of the revenue model increased at 0.5 , and the total investment decreased at the same time. By decreasing the revenue, the PP of the revenue model increased, and decreased when the total investment was reduced.

Table 7. Case evaluation.

\begin{tabular}{|c|c|c|c|c|c|}
\hline Case $\left(n, \alpha, \beta_{1}, \beta_{2}\right)$ & Model & $\frac{\Delta \text { Sales }^{*}}{\sum_{\mathbf{k}} \mathrm{F}_{\mathbf{k}} \mathbf{x}_{\mathbf{k}}}(\%)$ & $\frac{\Delta \text { Revenue }^{* *}}{\sum_{\mathbf{k}} \mathbf{F}_{\mathbf{k}} \mathbf{X}_{\mathbf{k}}}(\%)$ & $\frac{\Delta \mathrm{TCO}^{* * *}}{\sum_{\mathrm{k}} \mathrm{F}_{\mathbf{k}} \mathbf{x}_{\mathbf{k}}}(\%)$ & $\frac{\sum_{\mathbf{k}} \mathbf{F}_{\mathbf{k}} \mathbf{x}_{\mathbf{k}}}{\text { Revenue } \times 15 \%}($ years $)$ \\
\hline 1 & Sales & 27.61 & 76.41 & 0.53 & 3.93 \\
\hline$(3,0.3,1,1)$ & Revenue & 6.50 & 43.47 & 0.16 & 9.18 \\
\hline 2 & Sales & 35.71 & 88.88 & 0.71 & 3.02 \\
\hline$(3,0.5,1,1)$ & Revenue & 1.20 & 35.25 & 0.15 & 10.34 \\
\hline 3 & Sales & 53.15 & 116.10 & 1.04 & 2.03 \\
\hline$(3,0.7,1,1)$ & Revenue & 1.97 & 36.48 & 0.23 & 8.43 \\
\hline 4 & Sales & 58.18 & 124.17 & 1.20 & 1.75 \\
\hline$(3,1,1,1)$ & Revenue & 9.51 & 48.24 & 0.44 & 5.26 \\
\hline 5 & Sales & 45.84 & 91.44 & 0.92 & 2.48 \\
\hline$(5,1,1,1)$ & Revenue & $(11.14)^{* * * *}$ & 30.19 & 0.28 & 8.77 \\
\hline 6 & Sales & 27.61 & 53.08 & 0.56 & 4.56 \\
\hline$(10,1,1,1)$ & Revenue & 6.50 & 20.13 & 0.19 & 13.52 \\
\hline 7 & Sales & 35.71 & 88.88 & 0.71 & 3.02 \\
\hline$(3,1,1,0.5)$ & Revenue & 1.20 & 35.25 & 0.15 & 10.34 \\
\hline 8 & Sales & 27.61 & 63.08 & 0.55 & 4.26 \\
\hline$(5,1,1,0.5)$ & Revenue & 6.50 & 30.13 & 0.18 & 11.24 \\
\hline 9 & Sales & 19.45 & 40.26 & 0.38 & 6.68 \\
\hline$(10,1,1,0.5)$ & Revenue & 9.13 & 24.19 & 0.20 & 12.49 \\
\hline 10 & Sales & 92.11 & 176.85 & 1.91 & 0.97 \\
\hline$(3,1,1,2)$ & Revenue & 39.67 & 95.05 & 1.19 & 1.89 \\
\hline 11 & Sales & 68.16 & 125.90 & 1.41 & 1.51 \\
\hline$(5,1,1,2)$ & Revenue & 29.20 & 65.59 & 0.83 & 3.03 \\
\hline 12 & Sales & 45.84 & 81.44 & 0.94 & 2.58 \\
\hline$(10,1,1,2)$ & Revenue & 22.69 & 45.42 & 0.56 & 4.81 \\
\hline
\end{tabular}

$* \mathrm{y}-\mathrm{y}_{0}, * * \mathrm{y} \cdot \mathrm{PC}^{\prime}-\mathrm{y}_{0} \cdot \mathrm{PC}, * * * \mathrm{TCO}-\mathrm{TCO}^{\prime}, * * * *$ Negative.
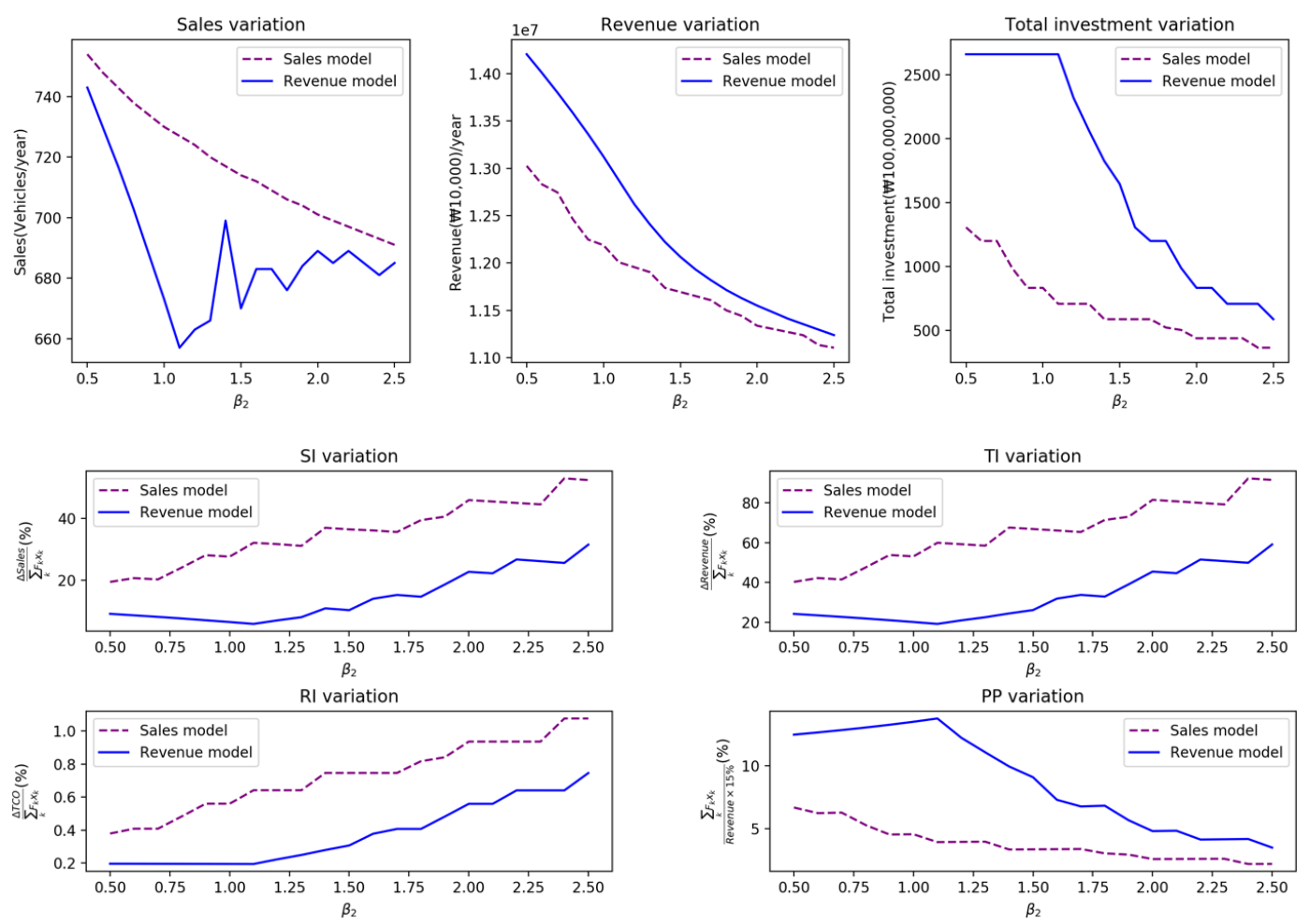

Figure 2. Trends in the models with the market change. 

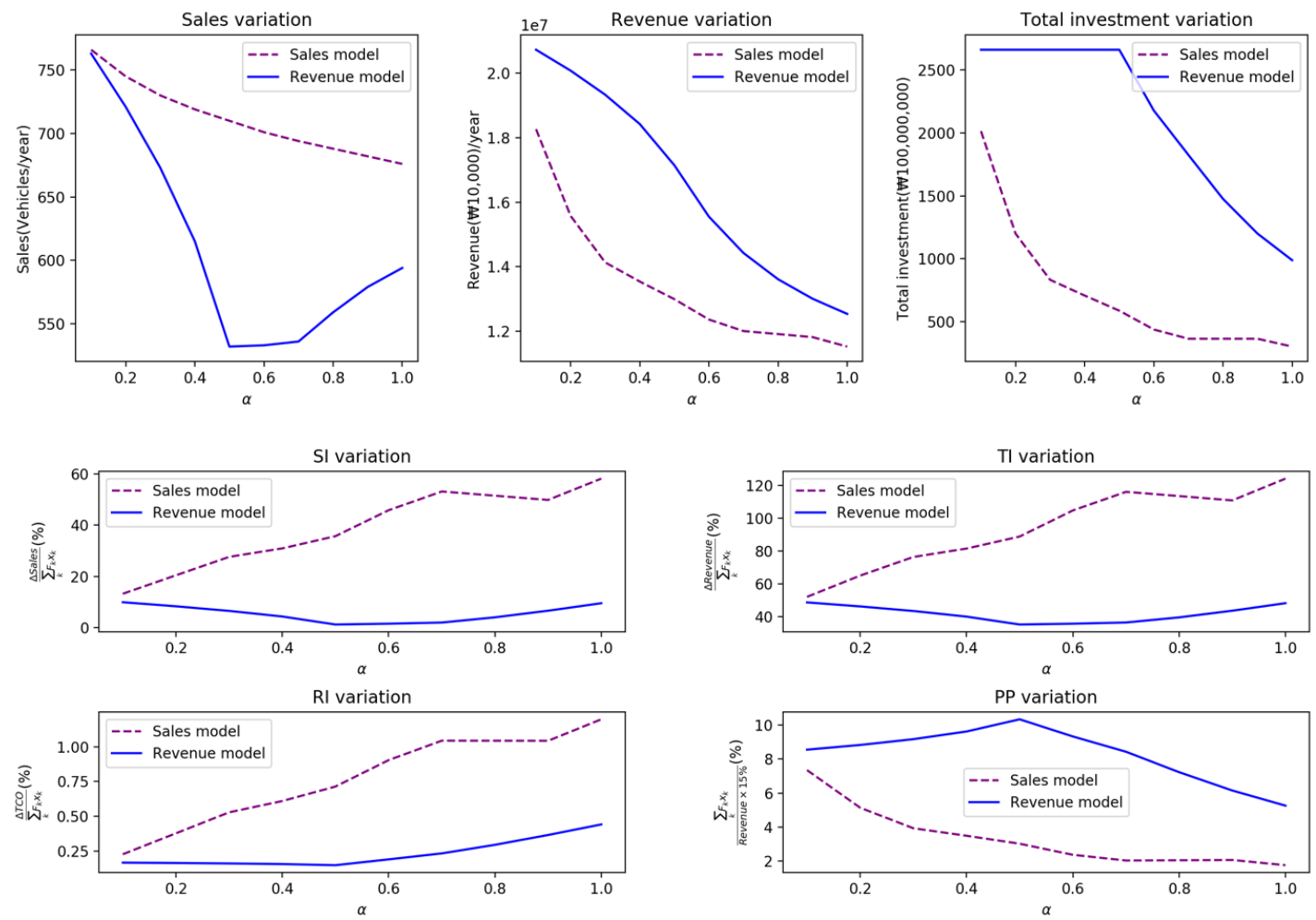

Figure 3. Trends in the models with the ratio of the total investment added to the PC.

\section{Conclusions}

Environmental issues are on the rise and regulations are becoming strict for companies. Recently, in the automobile industry, the new regulation EURO 6, which restricts emissions from exhaust gas more sternly, has been implemented and automobile manufacturers have been forced to institute new technologies for products to comply with the regulation. It is unavoidable that the purchase costs for these products will increase, which impacts on companies negatively due to the expensive purchase cost which may exclude their products as candidates for purchase by consumers. In order to nip this situation in the bud, companies need to consider the role of purchase cost increase in the process of selecting projects when developing a new product. In this study, the TCO approach was adopted and embedded in the project selection process to address solving environmental issues and minimizing the risk of customer churn incurred by purchase cost increases due to the need to invest in new projects.

The project selection problem and the TCO have been addressed in several fields over the past few decades. However, studies focusing on the integration of the TCO and project selection from the viewpoint of sales remain scarce. In the automobile industry, TCO has arisen as the main issue among customers, as the TCO is analyzed from their perspective. Automobile manufacturers provide the TCO calculator on their websites to show the TCO of their products to attract customers. Recently, electric vehicles (EVs) have become a large focal point in the industry, as manufacturers and research institutions are analyzing the prospect of EVs from the standpoint of TCO more actively.

In this study, a sales function was defined by combining the project developed and the TCO which impacts on customers' choices during product acquisition. By developing a new product, the investment in the project is added to the increase in the PC and the efficiency of the project reduces the MC. Therefore, increasing the PC is regarded as decreasing sales, and decreasing the MC is considered as increasing sales With the sales function, two project selection models were proposed, the sales and revenue models, to enhance business sustainability in the market as the representative strategies of companies. In the sales model, in order to increase the market share of the product, projects are selected at the proper level to maximize sales. In contrast, the revenue model selects the projects which maximize the profit of a company by selecting more projects. In the case of the automobile 
industry, where customers are sensitive to the TCO when choosing commercial vehicles, the results of the numerical example under the diversity cases showed the effective project selections according to the product sales planning $(n)$, the strategies of the purchase price $(\alpha)$, and the market situations $\left(\beta_{1}, \beta_{2}\right)$.

Thus, when companies develop a product, the proposed models help them in the decision-making process in terms of business sustainability. From an economic perspective, a new product which adds new technologies to cope with environmental regulations can incur a risk-the increase in the purchase cost of the new product can cause customers to exclude the product from consideration. The models solve such risk in the market by maximizing the sales and the revenue, respectively, on the basis of the proposed sales function. Simultaneously, business sustainability in terms of environmental issues is enhanced by increasing the lifecycle of items constituting the MC and the improvement in the product's performance, such as the increase in fuel efficiency. The key contribution of this study is in the superior presentation of the models by establishing a sales function which considers the TCO. The sales and revenue models show the correlation between the project and TCO, and the trends of the models were tested through experiments.

There are several issues of this study to be discussed. First, a limitation of this study is that the sales function was established by only the TCO. Despite the TCO being a significant factor affecting sales in the market, there are still a variety of factors to be considered. For example, the operating costs such as the promotional budget can be included. Moreover, depending on the products, the factors affecting sales may change. When the products customers are considering purchasing do not incur an expensive maintenance cost, the proposed sales function may not be appropriate in such a case.

Another issue are the project attributes, which consider only investment and efficiency. The duration of projects, the resources to carry out the projects, and the activities of the projects can also be considered as well as the different starting dates of the projects.

Future works might consider other factors affecting the sales of a product, conducting research on the relationship between the project and such factors. For example, assuming that competitors will prepare a similar product to release on the market, the duration of projects developing a product might be the most important. In this case, projects would be selected by analyzing the relationship between sales and the release date of the product. In addition, $\beta_{1}$ and $\beta_{2}$ can be developed to specify the market situations. In this study, the market situation, such as the same effort by competitors, was supposed in $\beta_{1}$ and $\beta_{2}$. By defining the relationships between a product of one company and those of competitors on the market more specifically, detailed sales can be considered when selecting projects.

More attributes of the project can be considered with sales, such as the synergies between projects and the different time of projects to be commenced. Also, the correlation between the efficiency and the costs of the product can be defined in detail and applied in the project selection model. Lastly, the uncertainty of the sales and the project can be addressed together, as uncertainties always exist out there.

Author Contributions: Conceptualization, S.L., Y.H.L., and Y.C.; Data curation, S.L.; Investigation, S.L.; Software, S.L.; Formal analysis, S.L., Y.H.L.; Validation, S.L., Y.H.L., and Y.C.; Supervision, S.L., Y.H.L.; Writing一 original draft, review, and editing, S.L.

Funding: This research received no external funding.

Conflicts of Interest: The authors declare no conflict of interest.

\section{References}

1. Muntean, M. Business intelligence issues for sustainability projects. Sustainability 2018, 10, 335. [CrossRef]

2. Tucki, K.; Mruk, R.; Orynycz, O.; Botwińska, K.; Gola, A.; Baczyk, A. Toxicity of exhaust fumes (CO, NOx) of the compression-ignition (diesel) engine with the use of simulation. Sustainability 2019, 11, 2188. [CrossRef]

3. Markowitz, H. Portfolio selection. J. Financ. 1952, 7, 77-91.

4. Meade, L.M.; Presley, A. R\&D project selection using the analytic network process. IEEE Trans. Eng. Manag. 2002, 49, 59-66. 
5. Amiri, M.P. Project selection for oil-fields development by using the AHP and fuzzy TOPSIS methods. Exp. Syst. Appl. 2010, 37, 6218-6224. [CrossRef]

6. Mohanty, R.; Agarwal, R.; Choudhury, A.; Tiwari, M. A fuzzy ANP-based approach to R\&D project selection: A case study. Int. J. Prod. Res. 2005, 43, 5199-5216.

7. Carlsson, C.; Fullér, R.; Heikkilä, M.; Majlender, P. A fuzzy approach to R\&D project portfolio selection. Int. J. Approx. Reason. 2007, 44, 93-105.

8. Pérez, F.; Gómez, T.; Caballero, R.; Liern, V. Project portfolio selection and planning with fuzzy constraints. Technol. Forecast. Soc. Chang. 2018, 131, 117-129. [CrossRef]

9. Mohagheghi, V.; Mousavi, S.M.; Vahdani, B.; Shahriari, M. R\&D project evaluation and project portfolio selection by a new interval type-2 fuzzy optimization approach. Neural Comput. Appl. 2017, 28, 3869-3888.

10. Dinesh Kumar, U.; Saranga, H.; Ramírez-Márquez, J.E.; Nowicki, D. Six sigma project selection using data envelopment analysis. TQM Mag. 2007, 19, 419-441. [CrossRef]

11. Eilat, H.; Golany, B.; Shtub, A. R\&D project evaluation: An integrated DEA and balanced scorecard approach. Omega 2008, 36, 895-912.

12. Liesiö, J.; Mild, P.; Salo, A. Preference programming for robust portfolio modeling and project selection. Eur. J. Operat. Res. 2007, 181, 1488-1505. [CrossRef]

13. Fliedner, T.; Liesiö, J. Adjustable robustness for multi-attribute project portfolio selection. Eur. J. Operat. Res. 2016, 252, 931-946. [CrossRef]

14. Lee, J.W.; Kim, S.H. An integrated approach for interdependent information system project selection. Int. J. Proj. Manag. 2001, 19, 111-118. [CrossRef]

15. Badri, M.A.; Davis, D.; Davis, D. A comprehensive 0-1 goal programming model for project selection. Int. J. Proj. Manag. 2001, 19, 243-252. [CrossRef]

16. Doerner, K.; Gutjahr, W.J.; Hartl, R.F.; Strauss, C.; Stummer, C. Pareto ant colony optimization: A metaheuristic approach to multiobjective portfolio selection. Ann. Operat. Res. 2004, 131, 79-99. [CrossRef]

17. Doerner, K.F.; Gutjahr, W.J.; Hartl, R.F.; Strauss, C.; Stummer, C. Pareto ant colony optimization with ILP preprocessing in multiobjective project portfolio selection. Eur. J. Operat. Res. 2006, 171, 830-841. [CrossRef]

18. Dewi, S. (Ed.) Combinatorial Optimization in Project Selection Using Genetic Algorithm. IOP Conference Series: Materials Science and Engineering; IOP Publishing: Bristol, UK, 2018.

19. Panadero, J.; Doering, J.; Kizys, R.; Juan, A.A.; Fito, A. A variable neighborhood search simheuristic for project portfolio selection under uncertainty. J. Heurist. 2018, 1-23. [CrossRef]

20. Lee, S.; Cho, C.; Choi, J.; Yoon, B. R\&D project selection incorporating customer-perceived value and technology potential: The case of the automobile industry. Sustainability 2017, 9, 1918.

21. Ellram, L.M. Total cost of ownership: An analysis approach for purchasing. Int. J. Phys. Distrib. Logist. Manag. 1995, 25, 4-23. [CrossRef]

22. Ellram, L.M.; Maltz, A.B. The use of total cost of ownership concepts to model the outsourcing decision. Int. J. Logist. Manag. 1995, 6, 55-66. [CrossRef]

23. Degraeve, Z.; Labro, E.; Roodhooft, F. An evaluation of vendor selection models from a total cost of ownership perspective. Eur. J. Operat. Res. 2000, 125, 34-58. [CrossRef]

24. Wouters, M.; Anderson, J.C.; Wynstra, F. The adoption of total cost of ownership for sourcing decisions-A structural equations analysis. Account. Organ. Soc. 2005, 30, 167-191. [CrossRef]

25. Faria, R.; Moura, P.; Delgado, J.; De Almeida, A.T. A sustainability assessment of electric vehicles as a personal mobility system. Energy Convers. Manag. 2012, 61, 19-30. [CrossRef]

26. Al-Alawi, B.M.; Bradley, T.H. Total cost of ownership, payback, and consumer preference modeling of plug-in hybrid electric vehicles. Appl. Energy 2013, 103, 488-506. [CrossRef]

27. Dumortier, J.; Siddiki, S.; Carley, S.; Cisney, J.; Krause, R.M.; Lane, B.W.; Rupp, J.A.; Graham, J.D. Effects of providing total cost of ownership information on consumers' intent to purchase a hybrid or plug-in electric vehicle. Transport. Res. Part A Policy Pract. 2015, 72, 71-86. [CrossRef]

28. Lin, C.; Wu, T.; Ou, X.; Zhang, Q.; Zhang, X.; Zhang, X. Life-cycle private costs of hybrid electric vehicles in the current Chinese market. Energy Policy 2013, 55, 501-510. [CrossRef]

29. Tseng, H.-K.; Wu, J.S.; Liu, X. Affordability of electric vehicles for a sustainable transport system: An economic and environmental analysis. Energy Policy 2013, 61, 441-447. [CrossRef] 
30. Wu, G.; Inderbitzin, A.; Bening, C. Total cost of ownership of electric vehicles compared to conventional vehicles: A probabilistic analysis and projection across market segments. Energy Policy 2015, 80, 196-214. [CrossRef]

31. Atkinson, R. Project management: Cost, time and quality, two best guesses and a phenomenon, its time to accept other success criteria. Int. J. Proj. Manag. 1999, 17, 337-342. [CrossRef]

32. Um, K.-H.; Kim, S.-M. Collaboration and opportunism as mediators of the relationship between NPD project uncertainty and NPD project performance. Int. J. Proj. Manag. 2018, 36, 659-672. [CrossRef]

33. Tran, D.H.; Long, L.D. Project scheduling with time, cost and risk trade-off using adaptive multiple objective differential evolution. Eng. Constr. Archit. Manag. 2018, 25, 623-638. [CrossRef]

34. Tofighian, A.A.; Moezzi, H.; Barfuei, M.K.; Shafiee, M. Multi-period project portfolio selection under risk considerations and stochastic income. J. Ind. Eng. Int. 2018, 14, 571-584. [CrossRef]

35. Litvinchev, I.; López, F.; Escalante, H.; Mata, M. A milp bi-objective model for static portfolio selection of R\&D projects with synergies. J. Comput. Syst. Sci. Int. 2011, 50, 942-952.

36. Li, X.; Fang, S.-C.; Guo, X.; Deng, Z.; Qi, J. An extended model for project portfolio selection with project divisibility and interdependency. J. Syst. Sci. Syst. Eng. 2016, 25, 119-138. [CrossRef]

37. Schaeffer, S.; Cruz-Reyes, L. Static R\&D project portfolio selection in public organizations. Decis. Support Syst. 2016, 84, 53-63.

38. Kaiser, M.G.; El Arbi, F.; Ahlemann, F. Successful project portfolio management beyond project selection techniques: Understanding the role of structural alignment. Int. J. Proj. Manag. 2015, 33, 126-139. [CrossRef]

39. Opinet. Available online: https://www.opinet.co.kr (accessed on 13 March 2019).

40. Hyundai Motors (Truck and Bus). Available online: https://www-trucknbus.hyundai.com/kr/experience/ fuel-consumption-contest/2016/driving-class1?sn=BL00000210 (accessed on 13 March 2019).

41. Hyundai Motors (Truck and Bus). Available online: https://www-trucknbus.hyundai.com/kr/service/partsearch-manual (accessed on 13 March 2019).

42. Traffic Newspaper. Available online: http://www.gyotongn.com/news/articleView.html?idxno=146658 (accessed on 1 April 2019).

(C) 2019 by the authors. Licensee MDPI, Basel, Switzerland. This article is an open access article distributed under the terms and conditions of the Creative Commons Attribution (CC BY) license (http://creativecommons.org/licenses/by/4.0/). 